\title{
Front Matter: Volume 9283
}

, "Front Matter: Volume 9283," Proc. SPIE 9283, 7th International Symposium on Advanced Optical Manufacturing and Testing Technologies: Design, Manufacturing, and Testing of Micro- and Nano-Optical Devices and Systems, 928301 (21 August 2014); doi: 10.1117/12.2082973

SPIE Event: 7th International Symposium on Advanced Optical Manufacturing and Testing Technologies (AOMATT 2014), 2014, Harbin, China 


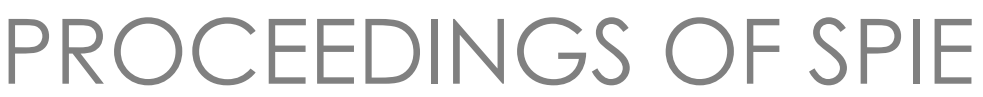

\section{7th International Symposium on Advanced Optical Manufacturing and Testing Technologies}

\section{Design Manufacturing, and Testing of Micro- and Nano-Optical Devices, and Systems}

Tianchun Ye

A.G. Poleshchuk

Song Hu

Editors

\section{6-29 April 2014}

Harbin, China

Sponsored by

COS-The Chinese Optical Society (China)

IOE-Institute of Optics and Electronics, Chinese Academy of Sciences (China)

Technical Cosponsor

SPIE

Supporting Organizations

Ministry of Science and Technology of China (China)

Chinese Academy of Sciences (China)

National Natural Science Foundation of China (China)

Published by

SPIE

Volume 9283 
The papers included in this volume were part of the technical conference cited on the cover and title page. Papers were selected and subject to review by the editors and conference program committee. Some conference presentations may not be available for publication. The papers published in these proceedings reflect the work and thoughts of the authors and are published herein as submitted. The publisher is not responsible for the validity of the information or for any outcomes resulting from reliance thereon.

Please use the following format to cite material from this book:

Author(s), "Title of Paper," in 7th International Symposium on Advanced Optical Manufacturing and Testing Technologies: Design, Manufacturing, and Testing of Micro- and Nano-Optical Devices and Systems, edited by Tianchun Ye, A. G. Poleshchuk, Song Hu, Proceedings of SPIE Vol. 9283 (SPIE, Bellingham, WA, 2014) Article CID Number.

ISSN: 0277-786X

ISBN: 9781628413588

Published by

SPIE

P.O. Box 10, Bellingham, Washington $98227-0010$ USA

Telephone +1 3606763290 (Pacific Time) · Fax +1 3606471445

SPIE.org

Copyright () 2014, Society of Photo-Optical Instrumentation Engineers.

Copying of material in this book for internal or personal use, or for the internal or personal use of specific clients, beyond the fair use provisions granted by the U.S. Copyright Law is authorized by SPIE subject to payment of copying fees. The Transactional Reporting Service base fee for this volume is $\$ 18.00$ per article (or portion thereof), which should be paid directly to the Copyright Clearance Center (CCC), 222 Rosewood Drive, Danvers, MA 01923. Payment may also be made electronically through CCC Online at copyright.com. Other copying for republication, resale, advertising or promotion, or any form of systematic or multiple reproduction of any material in this book is prohibited except with permission in writing from the publisher. The CCC fee code is 0277-786X/14/\$18.00.

Printed in the United States of America.

Publication of record for individual papers is online in the SPIE Digital Library.

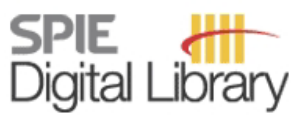

SPIEDigitalLibrary.org

Paper Numbering: Proceedings of SPIE follow an e-First publication model, with papers published first online and then in print and on CD-ROM. Papers are published as they are submitted and meet publication criteria. A unique, consistent, permanent citation identifier (CID) number is assigned to each article at the time of the first publication. Utilization of CIDs allows articles to be fully citable as soon as they are published online, and connects the same identifier to all online, print, and electronic versions of the publication. SPIE uses a six-digit CID article numbering system in which:

- The first four digits correspond to the SPIE volume number.

- The last two digits indicate publication order within the volume using a Base 36 numbering

system employing both numerals and letters. These two-number sets start with 00, 01, 02, 03, 04, $05,06,07,08,09,0 A, 0 B \ldots 0 Z$, followed by 10-1Z, 20-2Z, etc.

The CID Number appears on each page of the manuscript. The complete citation is used on the first page, and an abbreviated version on subsequent pages. Numbers in the index correspond to the last two digits of the six-digit CID Number. 


\title{
Contents
}

\author{
vii Symposium Committee \\ ix Introduction \\ xi AOMATT 2014 Sponsors
}

\section{ORAL SESSION}

928302 Diffractive optical elements: fabrication and application (Plenary Paper) [9283-57]

A. G. Poleshchuk, V. P. Korolkov, R. K. Nasyrov, Institute of Automation and Electrometry (Russian Federation)

928303 Analysis and optimization of a novel laterally deformable optical NEMS grating transducer [9283-6]

C. Wang, J. Bai, G.-G. Yang, Zhejiang Univ. (China)

928304 Experimental study on elliptical vibration cutting for optical microstructures [9283-47]

G. Li, L. Che, B. Wang, F. Ding, C. F. Zhang, Harbin Institute of Technology (China)

928305 A novel desktop device for lapping thin-walled micro groove [9283-28]

S. Wang, B. Wang, L. Che, F. Ding, D. Li, Harbin Institute of Technology (China)

928306 Space focusing mirror assembly with flexure hinges [9283-39]

Q. Guo, W. Li, J. Dong, Y. Li, K. Wang, Changchun Institute of Optics, Fine Mechanics and Physics (China)

928307 Simulation of internally referenced resonance in a three-layer-coated microsphere resonator [9283-24]

Y. Dong, X. Jin, K. Wang, Univ. of Science and Technology of China (China)

928308 Micromachined fiber optic Fabry-Perot underwater acoustic probe [9283-5]

F. Wang, Z. Shao, Z. Hu, H. Luo, J. Xie, Y. Hu, National Univ. of Defense Technology (China)

928309 A method for compensating the polarization aberration of projection optics in immersion lithography [9283-37]

Y. Jia, Y. Li, L. Liu, C. Han, X. Liu, Beijing Institute of Technology (China)

9283 OA Transmission characteristics analysis of a hybrid SNIMS plasmonic waveguide [9283-48]

M. Zhang, J. Ma, Shenzhen Univ. (China)

$9283 \mathrm{OB} \quad$ Vector simulation of pinhole diffraction behavior for high numerical aperture converging incident beam at deep ultraviolet wavelength [9283-35]

B. Liu, K. Liu, M. Zheng, L. Dong, Beijing Institute of Technology (China) 
9283 OC Methods on micro lens compact applied in zoom systems [9283-55]

H. Liu, Luoyang, Q. Ding, Luoyang Institute of Electro-Optical Equipment (China); L. Zhou,

Beijing Institute of Technology (China)

\section{POSTER SESSION}

9283 OD A novel measuring device for step gauge [9283-40]

S. Sun, X. Shen, L. Zou, H. Gao, X. Ye, National Institute of Metrology (China)

9283 OE 3D micropositioning control based on stereo microscopic visual servoing system [9283-8]

X. Sha, H. Li, S. Wang, Z. Li, G. Li, Yanshan Univ. (China)

9283 OF Effect of elastic modulus of PMMA films on its machinability by AFM-based nanoscratching method [9283-10]

Y. Yan, Y. Zhuang, Y. Geng, L. Cheng, J. Li, Harbin Institute of Technology (China)

9283 OG Multiple spectrum analysis and evaluation for optical constants of $\mathrm{HfO}_{2}$ thin films [9283-53]

D. Liu, H. Liu, C. Jiang, Y. Jiang, Tianjin Jinhang Institute of Technical Physics (China); L. Wang, Tianjin Jinhang Institute of Technical Physics (China) and Harbin Institute of Technology (China); Z. Zhao, Y. Ji, Tianjin Jinhang Institute of Technical Physics (China)

$9283 \mathrm{OH} \quad$ Study on the micro-milling of optical microstructure with the assist of the workpiece vibration [9283-44]

G. Li, F. Ding, B. Wang, L. Che, C. F. Zhang, Harbin Institute of Technology (China)

9283 Ol Design and analysis of drum lathe for manufacturing large-scale optical microstructured surface and load characteristics of aerostatic spindle [9283-52]

D. Wu, Z. Qiao, B. Wang, H. Wang, G. Li, Harbin Institute of Technology (China)

$92830 \mathrm{~J} \quad$ The dynamic analysis of drum roll lathe for machining of rollers [9283-50]

Z. Qiao, D. Wu, B. Wang, G. Li, H. Wang, F. Ding, Harbin Institute of Technology (China)

9283 OK Intelligent control system based on ARM for lithography tool [9283-16]

C. Chen, Institute of Optics and Electronics (China) and Univ. of Chinese Academy of Sciences (China); X. Tang, S. Hu, Institute of Optics and Electronics (China); N. Wang, Institute of Optics and Electronics (China) and Univ. of Chinese Academy of Sciences (China)

9283 OL Design of a projection objective with high numeric aperture and large view field [9283-25] J. Liu, Institute of Optics and Electronics (China) and Univ. of Chinese Academy of Sciences (China); S. Hu, H. Gao, L. Zhao, X. Zhu, Institute of Optics and Electronics (China)

9283 OM Optical property simulation of liquid crystal on silicon based on finite-difference timedomain method [9283-43]

H. Li, C. Shen, L. Ni, K. Liu, S. Wei, Anhui Univ. (China)

9283 ON Design of a micro lapping system based on double-feedback control algorithm for manufacturing optical micro components [9283-17]

L. Che, G. Li, B. Wang, F. Ding, X. Mao, W. Dong, Harbin Institute of Technology (China) 
$928300 \quad$ Experimental study on lapping of micro groove with controlled force [9283-49]

F. Ding, B. Wang, G. Li, L. Che, X. Mao, Harbin Institute of Technology (China)

$9283 \mathrm{OP}$ The polarization maintaining and polarization-basis calibrating in the free-space quantum communication system [9283-11]

Q. Zhang, Institute of Optics And Electronics (China) and Univ. of Chinese Academy of Sciences (China); Y. Huang, Institute of Optics And Electronics (China); J. Ren, Univ. of Science and Technology of China (China)

$92830 Q \quad$ ASCOM based research on the universal control protocol of telescope [9283-12] P. Wu, Institute of Optics and Electronics (China) and Univ. of Chinese Academy of Sciences (China); C. Luo, Institute of Optics and Electronics (China)

9283 OR Fabrication of resonant subwavelength grating based on thiol-ene [9283-15] M. Zhang, Q. Deng, L. Shi, Z. Li, H. Pang, Y. Zhang, J. Yu, S. Hu, Institute of Optics and Electronics (China)

9283 OS Design and preparation of film for microsphere based optical super-resolution imaging [9283-20]

H. Pang, Institute of Optics and Electronics (China) and Univ. Of Electronic Science and Technology of China (China); C. Du, Chongqing Institute of Green and Intelligent Technology (China); Q. Qiu, Univ. of Electronic Science and Technology of China (China); S. Yin, Chongaing Institute of Green and Intelligent Technology (China); M. Zhang, Q. Deng, Institute of Optics and Electronics (China)

9283 OT Visible stealth materials based on photonic crystals [9283-38] G. Yao, Y. Liu, Academy of Armored Forces Engineering (China)

9283 OU Design and performance of a wide-angle infrared plasmonic absorber [9283-3] X. Ming, Q. Tan, Tsinghua Univ. (China)

9283 OV Nonlinear optical and optical limiting properties of graphene oxide dispersion in femtosecond regime [9283-45]

Z. Zheng, L. Zhu, F. Zhao, Sun Yat-Sen Univ. (China)

9283 OW Broadband optical concentration technology based on grating side-coupling [9283-51] L. Lu, K. Wang, Zhejiang Univ. (China)

$92830 \mathrm{X} \quad$ Integral imaging system with a soft substrate [9283-29]

Y. Zhang, Sichuan Univ. (China), Institute of Optics and Electronics (China), and Chongqing Institute of Green and Intelligent Technology (China); J. Du, Sichuan Univ. (China); H. Pang, Q. Deng, L. Shi, Institute of Optics and Electronics (China); S. Yin, C. Du, Chongqing Institute of Green and Intelligent Technology (China); X. Dong, Institute of Optics and Electronics (China); Z. Zhang, Sichuan Univ. (China); M. Zhang, J. Yu, Institute of Optics and Electronics (China)

9283 OY Uncertainties evaluations in the ray-tracing algorithm based on Monte Carlo method [9283-9]

G. Feng, P. Li, Y. He, Y. Wang, H. Wu, National Institute of Metrology (China) 
$9283 \mathrm{OZ}$ A hybrid algorithm for the design of diffractive optical element for beam shaping [9283-7] K. Yin, Institute of Optics and Electronics (China) and Univ. of Chinese Academy of Sciences (China); Z. Huang, W. Lin, T. Xing, Institute of Optics and Electronics (China)

928310 Optical trapping force and sensing detection research based on optical fiber shapes and transmission modes [9283-56]

H. Jiang, Lanzhou Univ. (China); Y. Liang, Northwest Institute for Nonferrous Metal Research (China); P. Cao, Q. Shao, Lanzhou Univ. (China); Q. Meng, People's Liberation Army (China)

928311 Double drive modes unimorph deformable mirror for femtosecond laser beam wavefront correction [9283-54]

Y. Liu, J. Chen, Univ. of Science and Technology of China (China); J. Ma, Ningbo Univ. (China); B. Li, J. Chu, Univ. of Science and Technology of China (China)

928312 Analysis and correction of drift-induced distortions on quantitative SPM surface roughness evaluations [9283-70]

T. Luo, Y. Chen, W. Huang, Univ. of Science and Technology of China (China); S. Gao, National Institute of Metrology (China)

928313 Measuring the polarization aberration of hyper-NA lens from the vector aerial image [9283-33]

L. Dong, Y. Li, X. Dai, H. Liu, K. Liu, Beijing Institute of Technology (China)

928314 Research development of thermal aberration in 193nm lithography exposure system [9283-32]

Y. Wang, Institute of Optics and Electronics (China) and Univ. Of Electronic Science and Technology of China (China); Y. Liu, Univ. of Electronic Science and Technology of China (China)

Author Index 


\title{
Symposium Committee
}

\author{
Honorary Chair \\ Bingkun Zhou, Chinese Optical Society (China) \\ Symposium General Chair \\ Liwei Zhou, Beijing Optical Society (China) \\ Symposium General Co-chairs \\ Jianlin Cao, Ministry of Science and Technology of China \\ H. Philip Stahl, NASA Marshall Space Flight Center (United States) \\ Yudong Zhang, Institute of Optics and Electronics (China) \\ Larry Stepp, Thirty Meter Telescope Project (United States) \\ Yingchun Liang, Harbin Institute of Technology (China) \\ Yu Yao, Harbin Engineering University (China) \\ International Academic Committee \\ Wenhan Jiang, Chair, Chinese Academy of Engineering (China) \\ Liwei Zhou, Chinese Academy of Engineering (China) and Beijing \\ Institute of Technology (China) \\ Harald Giessen, University of Stuttgart (Germany) \\ Junhua Pan, Chinese Academy of Engineering (China) and \\ Soochow University (China) \\ Myung K. Cho, National Optical Astronomy Observatory \\ (United States) \\ Organizing Committee
}

Yudong Zhang, Co-chair, IOE, CAS (China)

Jinghua Cao, Co-chair, Bureau of International Cooperation, CAS (China)

Libin Xiang, Co-chair, Shanghai Engineering Center for Microsatellites (China)

Yadong Jiang, Co-chair, University of Electronic Science and Technology (China) 
Program Committee

Xiangdi Lin, Chair, Chinese Academy of Engineering (China)

Hu Yang, Co-chair, IOE, CAS (China)

Wei Gao, Co-chair, Tohoku University (Japan)

Huadong Yu, Co-chair, Changchun University of Science and Technology (China)

Secretary General of the Symposium

Li Yang, Committee of Optical Manufacturing Technology, COS (China)

Session Chairs

$\begin{array}{ll}\text { Session 1-1 } & \text { Fan Wu } \\ \text { Session 2-1 } & \text { Qiming Xin } \\ \text { Session 3-1 } & \text { Shangming Wen } \\ \text { Session 4-1 } & \text { Tingwen Xin } \\ \text { Session 5-1 } & \text { Xiao Wang } \\ \text { Session 6-1 } & \text { Xiangang Luo } \\ \text { Session 1-2 } & \text { Bin Fan } \\ \text { Session 2-2 } & \text { Shengyi Li } \\ \text { Session 3-2 } & \text { Rongzhu Zhang } \\ \text { Session 4-2 } & \text { Qingliang Zhao } \\ \text { Session 5-2 } & \text { Yige Qi } \\ \text { Session 6-2 } & \text { Changtao Wang }\end{array}$




\section{Introduction}

The 7th International Symposium on Advanced Optical Manufacturing and Testing Technology (AOMATT) was held 26-29 April 2014 at the Harbin International Conference Center, China.

AOMATT 2014 was kicked off with a formal opening ceremony. The ceremony started with the introduction of VIP guests, symposium chairs, conference chairs, and plenary speakers, followed by opening speeches by Prof. Liwei Zhou, AOMATT 2014 Symposium Chairman, Prof. Bin XU, Vice President of IOE, a sponsor of AOMATT 2014, and Prof. Yingchun Liang, Assistant President of Harbin Institute of Technology, a local co-sponsor of AOMATT 2014. Dr. H. Philip Stahl, 2014 President of SPIE, technical cosponsor of AOMATT 2014, could not attend the symposium this year due to a schedule conflict, but sent his congratulation letter. In his letter, Dr. Stahl gave high marks for AOMATT and stated:

AOMATT is a very successful collaboration between SPIE, the Institute of Optics and Electronics of the Chinese Academy of Sciences, and the Chinese Optical Society. It has become a well-known international symposium on advanced optical manufacturing and testing technologies. The vision of AOMATT is closely aligned with SPIE's mission to promote optics and photonics around the world.

All of the conference sponsors and attendees greatly appreciate SPIE and Dr. Stahl's long-standing support of AOMATT since its inception in 2002.

The plenary sessions started immediately after the conclusion of the opening ceremony. There were a total of nine plenary presentations: Dr. Larry Stepp, Telescope Department Head for the Thirty Meter Telescope (TMT) Project, USA, presented "Manufacturing the Optics for the Thirty Meter Telescope"; Dr. Bernard Delabre, Optical Design Engineer of European Southern Observatory (ESO), Germany, presented "The Progress of the European Extremely Large Telescope"; Dr. Tao Sun, Director of the Centre for Precision Engineering(CPE) of Harbin Institute of Technology, presented "Method and procedure for the highefficiency and ultra-precision diamond turning of large optical mirrors"; Dr. Wei Gao, Professor and Director of Research Center for Precision Nanosystems, Dept. of Nanomechanics of Tohoku University, Japan, presented "Precision nanometrology for fabrication of micro optics"; Dr. Xuejun Zhang, Vice President of Changchun Institute of Optics, Fine Mechanics and Physics (CIOMP), CAS, presented "Advanced manufacturing and testing technologies for multiple mirror space telescopes"; Dr. A.G. Poleshchuk, Head of the Laboratory of Diffractive Optics, and Dr. Victor P. Korolkov, senior scientist of Institute of Automation and Electrometry, Siberian Branch of Russian Academy of Sciences, Novosibirsk, Russia, presented "Diffractive optical elements: fabrication and application"; Dr. 
Axel Schindler, Science and Technology Consultant of Leibniz Institute of Surface Modification (IOM), Germany, presented "Advanced ion beam finishing and atmospheric plasma technology for high end optics"; Dr. Harald Giessen, Chair for Ultrafast Nano-Optics in the Department of Physics at the University of Stuttgart, Germany, presented "Complex hybrid plasmonics: new materials and new functionalities"; Dr. Xiangang Luo, Director of State Key Laboratory of Optical Technologies on Nano-Fabrication and Micro-Engineering of Institute of Optics and Electronics, CAS, presented "Manipulating the polarization states of electromagnetic waves using subwavelength structures". More than 600 people attended the opening ceremony and the full-day plenary sessions.

More than 400 oral and poster papers were selected for AOMATT 2014. About 102 oral papers were presented in six parallel conference sessions on 27 April. A special Technical Workshop was held in the morning of 28 April. An all-symposium poster session was held in the afternoon of 28 April. Authors and attendees had active discussions and exchange of ideas throughout the symposium. Many papers presented cutting-edge research and development work in optical design, manufacturing, and testing. The success of AOMATT 2014 continued the tradition of focus and excellence of this biannual international topical symposium in China.

We would like to express our sincere appreciation to COS-The Chinese Optical Society, IOE-Institute of Optics and Electronics, Chinese Academy of Sciences, and to SPIE for sponsoring and supporting AOMATT 2014. We would like to thank all chairs, committee members, authors, and attendee for their contributions to the symposium and sharing their research with colleagues around the world.

The 8th AOMATT is planned for 2016, and we look forward to seeing everyone at AOMATT 2016. Please watch for the Call for Papers and symposium announcements on the SPIE, IOE and COS web sites. 


\section{AOMATT 2014 SPONSORS}

Sponsored by

COS-The Chinese Optical Society

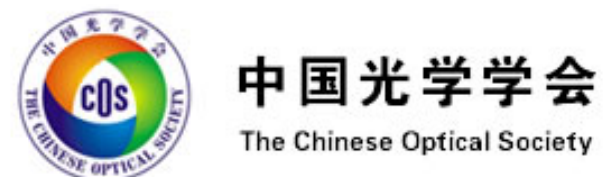

IOE-Institute of Optics and Electronics, Chinese Academy of Sciences

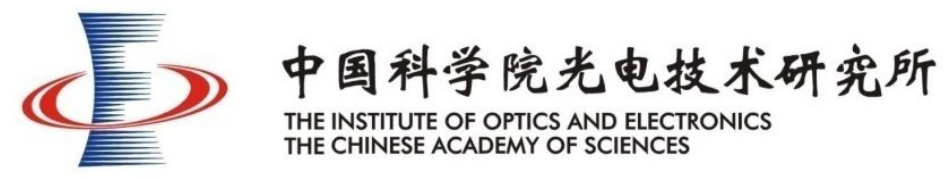

Technical Cosponsor

SPIE

\section{SPIE.}

Supporting Organizations

Ministry of Science and Technology of China

Chinese Academy of Sciences

National Natural Science Foundation of China

Cooperating Organizations

Harbin Institute of Technology (China) • Harbin Engineering University (China) • National University of Defense Technology (China) - University of Electronic Science and Technology of China - Sichuan University (China) - Sichuan Optical Society - State Key Laboratory of Optical Technologies on Nano-Fabrication and Micro-Engineering, IOE, CAS • Key Laboratory of Adaptive Optics, IOE, CAS • Changchun Institute of Optics, Fine Mechanics and Physics (China) - Beijing Institute of Technology (China) • Changchun University of Science and Technology (China) 